it should consider earnestly the effects upon medical practice, education and research of the modern pre. payment schemes. A new Committee of Medicine and the Changing Order has been appointed to consider this question. Dr. Baehr also referred to the success of the new (twelfth) Microbiological Section of the Academy and to the great services performed by the Library, which is one of the largest in the world.

Dr. B. P. Watson, the incoming president, has spent most of his life as a teacher and thus becomes the head of an educational institution devoted to the needs of the medical profession, the layman and the community as a whole. He reminded his audience that present-day medicine is the result of a slow process of evolution, in which the scientific approach to medicine has played a part since "the beginnings of recorded time". This evolution is the result of the interplay between research workers, reactionaries opposed to change, extremists who wish to proceed too quickly and the backbone of the profession, composed of steady, experimental thinkers who await the results of experiments and give the individual and the community the best that the profession can offer. Dr. Watson felt that any plans for a compulsory national health insurance that could be instituted now would lower the quality of medical care provided and would give the individual medical practitioner a task that he could not perform with satisfaction either to himself or to his patients. The Academy recognizes the need for improvement in the distribution of medical care, so that everyone can have it, but it pleads for continuing study and development, so that the best medical service and better teaching and research may result. In the course of his address, Dr. Watson discussed medical education, emphasizing, as the Goodenough Report on British Medical Schools has done, the teaching of principles, the integration of details learnt and the infusion into the teaching of more of the philosophical thought bequeathed to us by the past and nowadays "forgotten in the hectic pursuit of each newly-discovered fact"

\section{Forettry in Uganda : Report for 1947}

THE annual foyrt of the Forest Department of Uganda Pretsetorate for the year ended December 31, 1947, las recently been published (Entebbe: Goyt. (ithter, 1948 ; price $2 s$. 6d.). This report of 49 pages commences, as a number of recent forest reports from Africa have done, by a declaration of Government forest policy, which is on the familiar lines that have often been referred to in Nature in connexion with forestry notes. The forest policy during 1947 was considerably implemented as the report shows; it was to some extent the result of the Development Plan for Uganda put forward by Dr. E. B. Worthington which was approved by the Legislative Council during the year. This plan provided for the Forest Department receiving the sum of $£ 205,500$ to be spent in the ten years 1947-56 on expansion and development schemes, and this sum was to be in addition to the ordinary normal recurrent expenditure. As the amounts to be spent from this allocation for work only included soft-wood timber plantations, fuel planting-schemes, and research and investigation, hardwood-timber planting schemes apparently are to be covered by normal recurrent expenditure. This appears to be a pity, since it would soem that the indigenous hardwoods of Uganda may be neglected. Anti-malaria plantations were formed, at the request of the medical and health authorities, and the Department meant to clear-fell and replant them at intervals as an addition to the fuel supplies; but the health authority has been against clearfelling, and the plantations will be managed on the selection felling basis. The reservation of more forest has been proceeding, but it is pointed out that the distribution of forest is not all that could be wished for, particularly in parts of the Eastern Province; nor is it hoped to be able to make further reserves, and this leaves one with village forests as the altern ative. It is noteworthy in this report that the importance of the savannah forest has now come to be understood. In fact, it is stated that the greater part of Uganda is covered by this type of forest growth, and it is from the savannah rather than from closed forest that the demands of people for forest produce are chiefly met. It is a welcome sign that the formerly neglected savannah or 'bush' is now coming into recognition and, even more, that it is to be classified as 'forest'.

\section{Hormones and 'Drop' of Apple Fruits

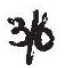

THE abscission or dropping of apple and other fruits after fertilization is sometimes a valuable natural method of ning the crop, but is often the source of man loss of fruit. L. C. Luckwill has studied the rflation to this 'drop' of a hormone optirrin in apple seeds (J.Hort. Sci., 24, No. 1, 32 ; $\mathrm{Ju} \mathrm{S}^{2}$ (4). He devised a quantitative method of measuring the hormone extract by treatment of tomato ovaries (ibid., 19) and was able to show that the appearance of the hormone in the seed coincided with cessation of the post-blossom drop. In the variety Beauty of Bath, the hormone appeared 25-30 days after petal-fall. Seeds of nearly ripe apples had little hormone, and its disappearance corresponded with the occurrence of pre-harvest dropping of the fruit. Moreover, seeds from 'June-drop' fruitlets of two other varieties contained much less hormone than those of fruits which remained on the tree. This hormone can be extracted from the seeds with boiling water, and though it stimulates the development of tomato ovaries, it does not appear to initiate fruit growth in the apple. It does, in fact, appear to be concerned chiefly with the control of fruit drop.

\section{Markle Foundation Scholarships in Medicine}

UNDER the plan begun in 1948 by the John and Mary R. Markle Foundation to assist qualified men and wopnen wishing to remain in academic medicine, thirten men of science have been awarded grants of 5,000 dollars a year, for five years, to maintain them in the medical schools of the United States and Canada in which they now hold faculty appointments. So far, twenty-nine such awards have been made. The thirteen new recipients, their fields of interest, and place of present appointment are as follow : Dr. Francis P. Chinard (University of California and Johns Hopkins), clinical chemistry and physiology, at Johns Hopkins University; Dr. Don W. Faweett (Harvard), microscopic anatomy, at Harvard Medical School; Dr. Allan V. N. Goodyer (Yale), internal medicine and cardiovascular disease, at Yale Univ. ersity; Dr. John B. Graham (Cornell), pathology, at the University of North Carolina; Dr. John D. Green (Oxford), anatomy and physiology, at Wayne University College of Medicine; Dr. George Watson James, III (Washington and Lee University), internal medicine and physiology, at the Medical College of Virginia; Dr. Ralph Jones, jun. (West Virginia 
University and University of Pennsylvania), clinical therapeutics, at the University of Pennsylvania; Dr. George E. Moore (University of Minnesota), surgery and onocology, at the University of Minnesota; Dr. C. Barber Mueller (University of Illinois and Washington University), surgery and biochemistry, at Washington University ; Dr. George W. Schwert, jun. (University of Minnesota), physical biochemistry, at Duke University; Dr. Beverly T. Towery (Vanderbilt), internal medicine and endocrinology, at Vanderbilt University; Dr. W. Clarke Wescoe (Cornell), pharmacology, at Cornell Univers. ity; Dr. Donald R. Wilson (Oxford and McGill), internal medicine and endocrinology, at the University of Alberta.

\section{Scholarships in the United States for British Students}

THe Coloraro School of Mines is offering a scholarship to a mole student from England for the academic year 1949-50. A separate offer is being made for Scotland. The scholarship is worth 425-475 dollars and 19 renewable for a maximum period of four years. Furcher particulars and application forms may be obtained from the Assistant Cultural Officer, U.S. Information Service, American Embassy, 5 Grosvenor Square, London, W.1, or from the secretary, Association of Universities of the British Commonwealth, 5 Gordon Square, London, W.C.1, with whom application forms must be lodged by May 1.

Harvard University announces that a fellowship, worth 2,000 dollars, provided by Mrs. Frank Knox in connexion with the Frank Knox Memorial Foundation, will be made available to enable a student from the British Isles to spend the academic year 1949-50 at Harvard. The fellowship is open to students of all stages; but preference will be given. to candidates who have graduated or are about to graduate in Great Britain or Ireland. There is no form of application. Further particulars can be obtained from the Secretary, Association of Universities of the British Commonwealth; applications must be completed by April 9 .

\section{International Conférence on Science Abstracting}

AN International Conference on Science Abstracting is to be held by Unesco in Paris during June 20-25. All Unesco and United Nations Member States will be entitlod to nominate three delegates. Representatiyes have also been invited from the specialized agencies of the United Nations and from the approprige international organisations such as the International Scientific Unions, the International Federation for Documentation and the International Organisation for Standardization. It is expected that the directors and editors of many of the most important abstracting services will be present at the Conference. Unesco will be glad to receive applications from persons other than officially appointed representatives who wish to attend as observers. The purpose of the Conference will be : "to consider and take action to improve and develop abstracting services for the natural sciences, both pure and applied, and to consider methods of increasing their usefulness to scientists, with regard at the same time to the related problems of indexing and accessibility of the recorded publications".

The Physical/Society: Seventy-fifth Anniversary Celebrations

THE celebration of the seventy-fifth anniversary of the Physical Society will take place on March 21. A conversazione will be held in the Royal Society's Rooms, Burlington House, Piccadilly, London, W.1, during 8-11 p.m., with the president, Prof. G. I. Finch, and Mrs. Finch as hosts. Admission is by ticket only. Earlier in the day, at 5 p.m., the Guthrie Lecture will be delivered by Prof. A. O. Rankine at the Royal Institution, 21 Albemarle Street, London, W.1, the subject being "Experimental Studies in Thermal Convection".

\section{Announcements}

MAJOR-Gganeral CYrIL Lloyd, director of Army Education, has been appointed administrative director of the Department of Technology of the City and Guilds of London Institute as from October 1, in succession to Lieut.-Colonel W. French.

A Davip Anderson Berry Silver-gilt Medal with a sum of $£ 100$ will be awarded in 1950 by the Royal Socigfy of Edinburgh for work on the therapeutical effect of X-rays on human diseases. Applications (with copies of accomplished work) must be sent to the General Secretary of the Royal Society of Edinburgh, 22 George Street, Edinburgh, 2, by March 31, 1950.

THE Arnold Gerstenberg Studentship for 1950 is open to students in the University of Cambridge who have obtained honours in the Natural Sciences Tripos and who went into residence not earlier than 1944 . The Studentship will be awarded for an essay which must be submitted before May 1, 1950; full details may be obtained from Mr. R. B. Braithwaite, King's College, Cambridge.

DR. K C. EDWARDs, reader in geography, has been appointed professor of geography, and Dr. E. J/W. Barrington, reader in zoology, has been appointed professor of zoology in the University of Nottingham. Both these chairs have just been established.

THE British Institute of Management will hold the fifty-thied in the 'Oxford' series of Management Conferences at Cliftonville during May 5-8. The form of the Conference has been altered, and the general purpose is to obtain a consensus of opinion among practising managers on certain fundamental and possibly controversial questions relating to the development of management, for the guidance of the Institute. Applications for tickets and all correspond. ence should be addressed to the Director, British Institute of Management, 17 Hill Street, London, W.l.

A воокLEx entitled "The Tilgate Story" has been issued by Messrs. F. W. Berk and Co., Ltd., of Commonwealth House, 1-19 New Oxford Street, Wh.1. This deals in a general way with the firm's research work on soil sterilization, deficiencies of soil nutrients, mercurial seed dressings, mercurized turf sand for the control of moss, and other mercury and copper fungicides and insecticides.

Mathematical Tables and Other Aids to Computation is a quarterly journal which is published and sub. sidized by the U.S. National Research Council. Not only io it running at a loss, but also costs are rapidly moynting. A substantial increase in the number of subscribers is necessary in order to avoid either increasing the price or reducing the size of the journal. The subscription-rate is 4 dollars per year, and full details may be obtained from the National Research Council, 2101 Constitution Avenue, Washington 25, D.C. In Great Britain the rate is 258 , and the agent is Scientific Computing Service, Ltd., 23 Bedford Square, London, W.C.I. 